\title{
Aetiology of spheroidal degeneration of the cornea in Labrador
}

\author{
GORDON J. JOHNSON \\ From the International Grenfell Association, St Anthony, Newfoundland, and \\ Memorial University, St John's, Newfoundland, Canada
}

SUMmaRY To determine the aetiology of spheroidal degeneration of the cornea (Labrador keratopathy), total population surveys were conducted in 5 communities in coastal Labrador and northern Newfoundland. For 4 years records were also kept on all clinic patients aged 40 or more throughout the region. Both methods gave a peak prevalence at latitudes $55^{\circ}-56^{\circ}$ north. The greatest severity and earliest age of onset occurred around the same latitudes. Of the proposed environmental causative agents only ultraviolet radiation, reflected from ice and snow, explains the distribution of the disease. The high cumulative UV dosage is due to the unique geographical and climatic features of the region.

'Labrador keratopathy' was the title of the first paper describing a degeneration of the cornea which is common in Northern Newfoundland and Labrador. ${ }^{1}$ Morphologically similar keratopathy has been reported from many parts of the world, and the general term spheroid (or spheroidal) degeneration of the cornea has been proposed. ${ }^{2}$

There is agreement that the primary aetiological agent is exposure of the cornea to some climatic or external physical factor. In his original paper Freedman ${ }^{1}$ considered the possible influence of heredity and nutrition as aetiological factors, but neither he nor others have found support for either. The specific climatic or physical agents he proposed were low humidity, low temperature, microtrauma from wind-blown snow or ice particles, and solar radiation in the ultraviolet wavelengths. We have studied each of these suggested factors to determine which best explains the unusual geographical distribution of the disease in Eastern Canada.

\section{Materials and methods}

The geographical area of this study is the northern peninsula of the Island of Newfoundland and all of coastal Labrador. Three races live in the areaInuit (Eskimos), North American Indians, and Caucasian settlers. The approximate populations

Correspondence to Dr G. J. Johnson, Health Sciences Centre, Memorial University of Newfoundland, St John's, Newfoundland A1B 3V6, Canada. are Inuit 2500 (including those of mixed InuitCaucasian parentage), Indian 1100, and Caucasians 42000 .

SURVEY METHOD 1

Surveys of either the entire population or the entire population over the age of 25 were conducted in 5 communities, representing a range of latitudes, and the different ethnic groups (Table 1). Although these surveys were conducted in the autumn or winter months when families were not away fishing, it was nevertheless necessary to visit some homes in the evenings in order to see all the fit younger men who did not wish to come to the clinic. In the Indian community of Davis Inlet (latitude $55^{\circ} 55^{\prime}$ ) it was not found possible to obtain the full cooperation of the people aged 25-35; therefore for this latitude only the results for over $\mathbf{4 0}$ were used in the comparisons.

The people were seen first by the ophthalmic nurse, who noted all the settlements where the patient had lived, and the nature of his or her occupation in winter and summer, and the frequency with which the patient had experienced snow blindness.

On the reverse side of the same card the appearance of the cornea was sketched by the ophthalmologist. A Haag-Streit 900 slit-lamp was used at one nursing station, and for clinics at the base hospital at St Anthony. The Kowa portable slitlamp was taken to all the other nursing stations and smaller hospitals. A grading was then written down 
Table 1 Whole population surveys conducted

\begin{tabular}{|c|c|c|c|c|c|c|}
\hline \multirow[b]{2}{*}{ Date } & \multirow[b]{2}{*}{ Place } & \multirow[b]{2}{*}{ Latitude } & \multirow[b]{2}{*}{ Race } & \multirow[b]{2}{*}{$\begin{array}{l}\text { Ages } \\
\text { included }\end{array}$} & \multicolumn{2}{|c|}{ Population in that age group } \\
\hline & & & & & $\begin{array}{l}\text { Total number } \\
\text { in town }\end{array}$ & $\%$ examined \\
\hline Nov. 1974 & Harbour Deep & $50^{\circ} 23^{\prime}$ & Caucasian & $25+$ & 137 & $96 \%$ \\
\hline Feb. 1977 & Black Tickle & $53^{\circ} 28^{\prime}$ & Caucasian & all & 182 & $92 \%$ \\
\hline Sept. 1974 & *Makkovik & $55^{\circ} 5^{\prime}$ & *Caucasian & $25+$ & 65 & $97 \%$ \\
\hline \multirow[t]{2}{*}{ Oct. 1975} & Davis Inlet & $55^{\circ} 55^{\prime}$ & Indian & $40+$ & 29 & $83 \%$ \\
\hline & & & Inuit & all & 4197 & \\
\hline \multirow[t]{2}{*}{ Oct. 1977} & Nain & $56^{\circ} 33^{\prime}$ & Mixed & all & 253 & $87 \%$ \\
\hline & & & Caucasian & all & $89]$ & \\
\hline
\end{tabular}

*The adult Inuits living here in 1974 had all been moved there around 1959. They were not included in the figures for Makkovik but assigned to their more northerly settlement of origin (usually Hebron or Nutak), as were some of those living in Nain.

for the keratopathy, if present, without referring to the patient's history.

The Inuit and a few settlers were evacuated south from settlements at $58^{\circ} 10^{\prime} \mathrm{N}$ and $57^{\circ} 31^{\prime} \mathrm{N}$ around 1959 as part of Provincial Government policy. The results for all the older people from these 2 communities, who are now scattered in the villages further south, were included in the results for the total populations in Table 2 .

\section{SURVEY METHOD 2}

During the course of the routine eye clinics held between July 1973 and July 1976 and January to July 1977 , both in the hospitals and in the nursing stations throughout the area, separate records were kept on every individual aged 40 or older when seen. These were men and women who had either sought the advice of the ophthalmologist or who had been referred by the station nurse or a physician.

Table 2 Prevalence of grade 1 and more severe spheroidal degeneration in total populations (percentages)

\begin{tabular}{|c|c|c|c|c|c|}
\hline \multirow{3}{*}{$\begin{array}{l}\text { Location of } \\
\text { community- } \\
\text { latitude }{ }^{\circ} N\end{array}$} & \multirow{3}{*}{$\begin{array}{l}\text { Racial } \\
\text { group }\end{array}$} & \multicolumn{4}{|c|}{ Age groups } \\
\hline & & \multicolumn{2}{|c|}{ Males } & \multicolumn{2}{|c|}{ Females } \\
\hline & & $40+$ & $30+$ & $40+$ & $30+$ \\
\hline $50^{\circ} 23^{\prime}$ & Caucasian & 63 & 49 & 11 & 7 \\
\hline $53^{\circ} 28^{\prime}$ & Caucasian & 85 & 67 & 50 & 31 \\
\hline $55^{\circ} 5^{\prime}$ & Caucasian & 95 & 89 & 26 & 23 \\
\hline \multirow[t]{2}{*}{$55^{\circ} 55^{\prime}$} & Indian & 100 & $*$ & 77 & $*$ \\
\hline & Caucasian & 100 & 88 & 56 & 42 \\
\hline \multirow[t]{2}{*}{$56^{\circ} 33^{\prime}$} & Mixed & 95 & 80 & 53 & 42 \\
\hline & Inuit & 95 & 74 & 64 & 38 \\
\hline $57^{\circ} 31^{\prime}$ & Inuit & 90 & $*$ & 70 & $*$ \\
\hline $58^{\circ} 10^{\prime}$ & Inuit & 73 & $*$ & 38 & * \\
\hline
\end{tabular}

*Accurate figures not available.
The proportion of the population presenting themselves was similar in the different communities.

The methods of recording and examination were the same as for the total population studies.

Through the courtesy of Dr Arthur Leith (Montreal) and Dr Frank Timmermans (Zone Director, Frobisher Bay) it was possible to take part in eye clinics in Baffin Island. An American Optical slitlamp was used, otherwise the methods were identical. The results for 33 people aged 40 and over in Pangnirtung (latitude $66^{\circ} 10^{\prime} \mathrm{N}$ ) could therefore be compared with the figures from Labrador.

For the purpose of mapping the distribution of the condition each person was assigned to the latitude of the district where he had spent the major part of his working life.

\section{CLINICAL GRADING}

The grading of the condition used in this study differs slightly from that of Freedman ${ }^{1}$ and has been described and illustrated previously. ${ }^{3}$ It is summarised again here.

Grade 1 . The degeneration begins as a grey haze in the superficial cornea, close to the nasal and temporal margins of the cornea but usually separated from them by a clear zone. When examined by retroillumination with the high power of the slitlamp, the haze can be resolved into small grey deposits, which look like 'droplets', immediately beneath the epithelium. In grade 1 the deposits are restricted to a nasal and lateral strip in each cornea, but must be present at both margins of the corneas.

The term 'trace' has been used when there were a few scattered droplets rather than a vertical strip of involvement at each of these 4 sites, or when deposits could only be detected at 2 or 3 of these margins.

Grade 2. As the involvement becomes more severe the deposits extend toward the centre into the 
optic axis. If the central spheroids are not sufficiently numerous to reduce vision, it is classified as grade 2 . The disease remains restricted to the horizontal band of cornea normally exposed between the eyelids.

Grade 3. Grade 3 is reached when the central involvement over the pupils is sufficiently dense to reduce vision to any degree. At this stage the exposed band of the cornea appears as ground glass, even to the naked eye. Ten men are thought to have vision reduced in both eyes to the level of blindness $(6 / 60)$ solely or primarily due to spheroidal degeneration of the corneas.

Grade 4. A fourth, severe stage has been seen in 5 patients. The droplets appeared to have coalesced to form raised, brownish nodules.

\section{SOURCES OF ENVIRONMENTAL DATA}

Climatic and environmental data for testing against the geographical distribution of the keratopathy were obtained from a variety of sources.

Temperature, humidity, and wind velocity. Mean daily temperatures, relative humidity, vapour pressure, and wind velocities along the east coast of Canada were obtained for each month from the published Atlas of Climatic Maps (Canada Department of Transport, Meteorological Branch, 1967), from the Atmospheric Environment Service, Environment Canada, Bedford, Nova Scotia, and from the Arctic Meteorology Section, Canadian Climate Centre, Downsview, Ontario. Figures of the wind-chill factor were obtained from published charts. ${ }^{4}$

In addition to using average wind speeds we attempted to arrive at an index of the cumulative effect of the wind during the period at each latitude when snow was on the ground. Seventeen latitudes were considered for which monthly averages of wind velocity at coastal sites were available. The average period of snow cover over 3-4 years at each of these sites was obtained from the maps of Northern Hemisphere Snow and Ice Boundaries issued each week by the National Oceanic and Atmospheric Administration, National Environmental Satellite Service (NOAA/NESS). The analysis is based on imagery from several satellites, including Tiros N since January 1979. The results for each latitude were expressed as the number of snow covered months during which the average wind speed equalled or exceeded an arbitrarily chosen velocity of $18 \mathrm{miles} / \mathrm{h}(29 \mathrm{~km} / \mathrm{h})$.

Ultraviolet radiation. Calculations were made, for different latitudes, of the component of the solar ultraviolet which is reflected upwards from the ground during the months when it is covered by snow and the water by ice.
No direct measurements have yet been made in Canada of ultraviolet flux reaching the earth's surface. However, ozone measurements are available for 6 stations indicated in Table 5 (Appendix). These results were used by Sundararaman, St John, and Venkateswaran ${ }^{5}$ to calculate the UV flux reaching the earth at these locations. With their data, and with the approximations outlined in the Appendix, the total downward flux for 5 wavelengths and for 6 latitudes was calculated for each month of the year.

To determine those months and weeks of the year for which snow and ice remained on the ground at each of the 6 latitudes the following sources were used: (i) the weekly ice maps of the US Naval Polar Oceanographic Center, formerly the Fleet Weather Facility, Suitland; (ii) the weekly ice-limit charts published from satellite data by NOAA/NESS; and (iii) observations from the ground kindly supplied by nurses in the nursing stations.

The dates from the charts were averaged for the years available, and modified where necessary by the ground observations so that for each latitude an approximate date was derived for the appearance of snow and ice, and their break-up and disappearance in the spring or summer (Table 5, Appendix). The end-points were the dates when the ground was half covered by snow and when sea ice was firm enough to walk on. Total downward UV flux during this period of high reflectivity was then obtained from the monthly totals for each latitude, for each of the 5 wavelengths (a part of the total for a month being taken where the dates fell part of the way through that month). These figures were then multiplied by the approximate albedo (or reflectivity) 0.9 to give the total flux of ultraviolet light which could be reflected throughout the year towards the eyes of people working or travelling outdoors during the months of snow and ice (Fig. 1) (the total fluxes for wavelength $296.7 \mathrm{~nm}$ were too low to appear on the figure at this scale).

\section{Results}

\section{SURVEY METHOD 1}

When every individual aged 25 or over in the community located at latitude $50^{\circ} 23^{\prime}$ was examined, the severity increased with age. All of the men except 1 had lived an outdoor life, fishing in the summer, hunting on the ice and collecting wood in the snow in winter. Every male over 54 years had at least a trace of the condition - with 1 exception, a man aged 79. He was the exception that proved the rule: he had come in from the southern part of Newfoundland and had been a school teacher all his life.

The women in the same community manifested the disease later and less severely. The youngest 


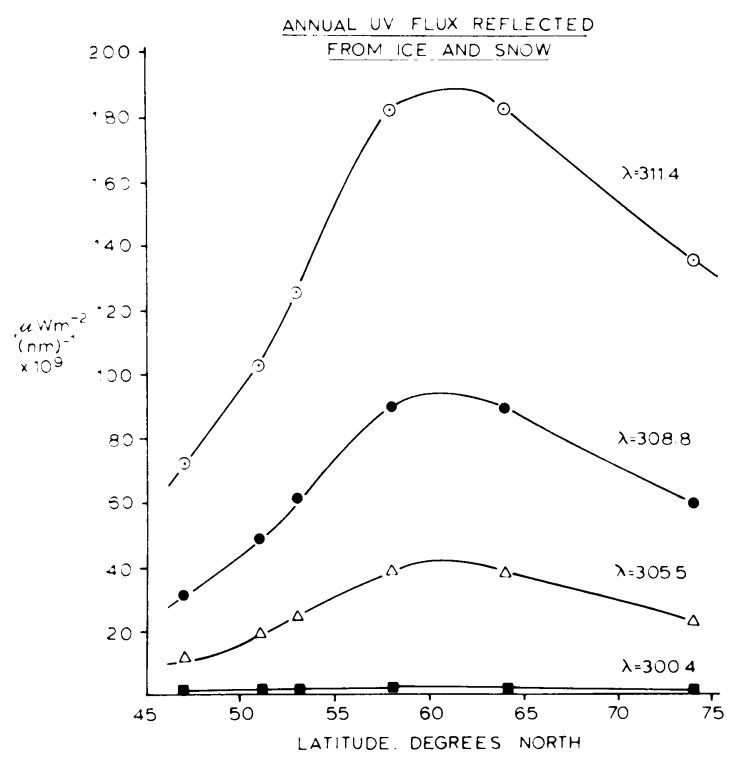

Fig. 1 Computed annual ultraviolet fluxes reflected from the ground surface during the months of ice and snow cover at 6 latitudes and for 4 wavelengths.

woman with grade 1 was 59 . None had keratopathy more severe than grade 1 .

At another settlement further north, at latitude $55^{\circ} 5^{\prime}$, there was a greater proportion of men with the severe grades and the disease appeared earlier in life. Grade 3 keratopathy occurred in a man of 44 , whereas the youngest with grade 3 at the previous location was 75 years. Similarly, the females here showed grade 1 at an earlier age (48) than at latitude $50^{\circ} 23^{\prime}$ ( 59 years).

The overall prevalences of spheroidal degeneration of all grades, from grades 1 to 4 but not including those with a trace, is given in Table 2 . The prevalences for each community are given in terms of different age groups. Those older Inuit who had lived most of their lives further north at latitudes such as $58^{\circ}$ and $59^{\circ}$ did not have keratopathy as severe as people of the same age and race who had always lived at $55^{\circ} 30^{\prime}$ or $56^{\circ} 33^{\prime}$. The impression was gained of a peak prevalence and severity around $55^{\circ}-56^{\circ} 33^{\prime}$, decreasing again north of this even within the boundary of Labrador.

The situation in the community of Nain $\left(56^{\circ} 33^{\prime} \mathrm{N}\right)$ is complex. Besides Inuit and Caucasian settlers who have lived there all their lives there is a large group with mixed Inuit-Caucasian parentage. The prevalences are nevertheless closely similar in the 3 racial groups.

A second way to assess the severity of the condition in a community was to determine the youngest age at which a particular grade occurred. The results in Table 3 reinforce the impression of a peak of severity around latitudes $55^{\circ}-56^{\circ}$.

\section{SURVEY METHOD 2}

When the percentages of men in the clinic population with keratopathy of grade 1 or greater severity were arranged according to the latitude where they had spent the major part of their working lives, Fig. 2 was obtained. There is a peak incidence around latitude $55^{\circ}$ to $56^{\circ}$ north. The curve for grade 2 or greater severity is similar (Fig. 2, lower bars).

The distribution for women in the general clinic population is also similar, though the peak incidence is slightly further north, around $57^{\circ}$, and the overall prevalence is lower (Fig. 3).

The results of the eye clinic conducted in Pang-

Table 3 Age of onset of spheroidal degeneration in total populations

\begin{tabular}{|c|c|c|c|c|c|c|c|}
\hline & \multirow{3}{*}{$\begin{array}{l}\text { Racial } \\
\text { group }\end{array}$} & \multicolumn{6}{|c|}{ Age of youngest affected patient } \\
\hline & & \multicolumn{3}{|l|}{ Males } & \multicolumn{3}{|c|}{ Females } \\
\hline & & $\underset{1}{\text { Grade }}$ & $\begin{array}{l}\text { Grade } \\
2\end{array}$ & $\begin{array}{l}\text { Grade } \\
3\end{array}$ & $\begin{array}{l}\text { Grade } \\
1\end{array}$ & $\begin{array}{l}\text { Grade } \\
2\end{array}$ & $\begin{array}{l}\text { Grade } \\
3\end{array}$ \\
\hline $50^{\circ} 23^{\prime}$ & Caucasian & 42 & 63 & 75 & 60 & $\mathrm{Nil}$ & Nil \\
\hline $53^{\circ} 28^{\prime}$ & Caucasian & 39 & 64 & 64 & 49 & Nil & Nil \\
\hline $55^{\circ} 5^{\prime}$ & Caucasian & 36 & 43 & 43 & 49 & Nil & Nil \\
\hline \multirow[t]{2}{*}{$55^{\circ} 55^{\prime}$} & Indian & $*$ & 49 & 63 & $*$ & Nil & Nil \\
\hline & Caucasian & 34 & 41 & 46 & 41 & 72 & Nil \\
\hline \multirow[t]{2}{*}{$56^{\circ} 33^{\prime}$} & Mixed & 33 & 41 & 66 & 38 & Nil & 77 \\
\hline & Inuit & 28 & 38 & 63 & 34 & 68 & 80 \\
\hline $57^{\circ} 31^{\prime}$ & Inuit & $*$ & 57 & Nil & $*$ & Nil & Nil \\
\hline $58^{\circ} 10^{\prime}$ & Inuit & $*$ & 59 & 60 & * & Nil & Nil \\
\hline
\end{tabular}

Nil = Nobody with that grade present in that community. *Accurate figures not available.

SPHEROIDAL DEGENERATION IN CLINIC PATIENTS MALES OVER 40 YEARS

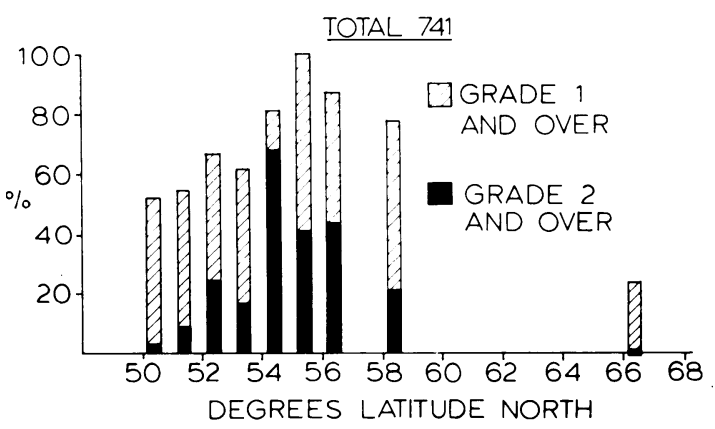

Fig. 2 Prevalence of spheroidal degeneration in men over 40 from different latitudes, attending routine eye clinics. 
SPHEROIDAL DEGENERATION IN CLINIC PATIENTS

\section{FEMALES OVER 40 YEARS}

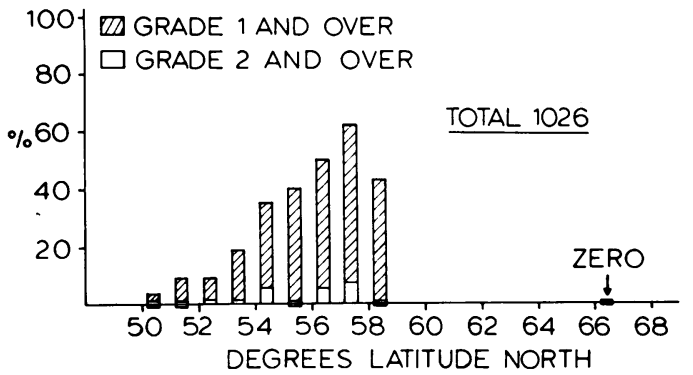

Fig. 3 Prevalence of spheroidal degeneration by latitude in females of same clinic population as in Fig. 2.

nirtung, Baffin Island, confirmed that the keratopathy was much less severe at latitude $66^{\circ}$. No male was encountered with more than grade 1 , and no female at this location had more than a trace of spheroidal degeneration.

During the period of study 77 people were also seen whose homes were in the centre or south of Newfoundland. Most of them had no spheroidal degeneration. Four of the 49 men showed grade 1 , and 1 (from latitude $49^{\circ} 45^{\prime}$ ) had grade 2. One of 28 women showed grade 1 degeneration.

These distribution curves therefore confirm the impressions obtained from a study of complete populations that the incidence and severity of the disease decrease steadily as one travels both north and south from a peak around latitudes $55^{\circ}-56^{\circ}$.

In the following comparisons with different possible aetiological agents the curve for the per- centage of males with grade 1 or greater severity (Fig. 2, upper bars) is used to represent these different measurements of the geographical distribution of the disease by latitude.

\section{CLIMATIC OR PHYSICAL AGENT}

Water content of the atmosphere, whether expressed as mean relative humidity, or as vapour pressure, becomes less towards the far north (Fig. 4). The values do not fit the distribution curve for spheroidal degeneration of the cornea. The mean vapour pressure in millibars was included to anticipate the argument that the total water content of the atmosphere might be more important than the relative humidity in producing a biological effect on the cornea.

At most latitudes February was the coldest month and April the time when hunters were most active outdoors. Temperature becomes progressively lower as one travels north (Fig. 5). If low temperature was the main cause, the spheroidal degeneration would be expected to be most severe in the high Arctic. The wind-chill factor takes into account both temperature and wind velocity. Its distribution does not fit the peak for the keratopathy either (Fig. 6).

Wind velocity considered alone, expressed as an average for the month of January, has a distribution by latitude quite different in shape from that for spheroidal degeneration (Fig. 7). The highest prevalence of the corneal degeneration, around latitude $55^{\circ}$, is in an area of relatively low mean wind speeds.

The results for the snow-covered months for which the average wind speed exceeds 18 miles/h $(29 \mathrm{~km} / \mathrm{h})$ are represented in Fig. 8. There is peak

MEAN RELATIVE HUMIDITY AND VAPOUR PRESSURE: FEBRUARY

Fig. 4 Geographical distribution of spheroidal degeneration compared with relative humidity and vapour pressure at different latitudes on the east coast of Canada. (In Figs. 4-9 the distribution of the corneal degeneration of grade 1 and greater severity in males in the general clinic population aged over 40 is taken as representative of the different determinations of the geographical distribution of the condition.)

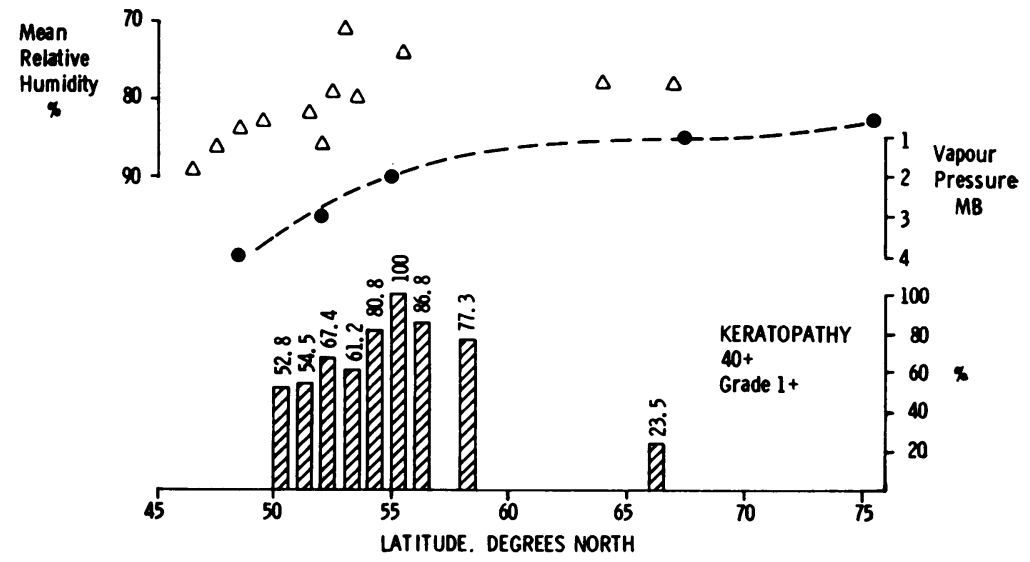




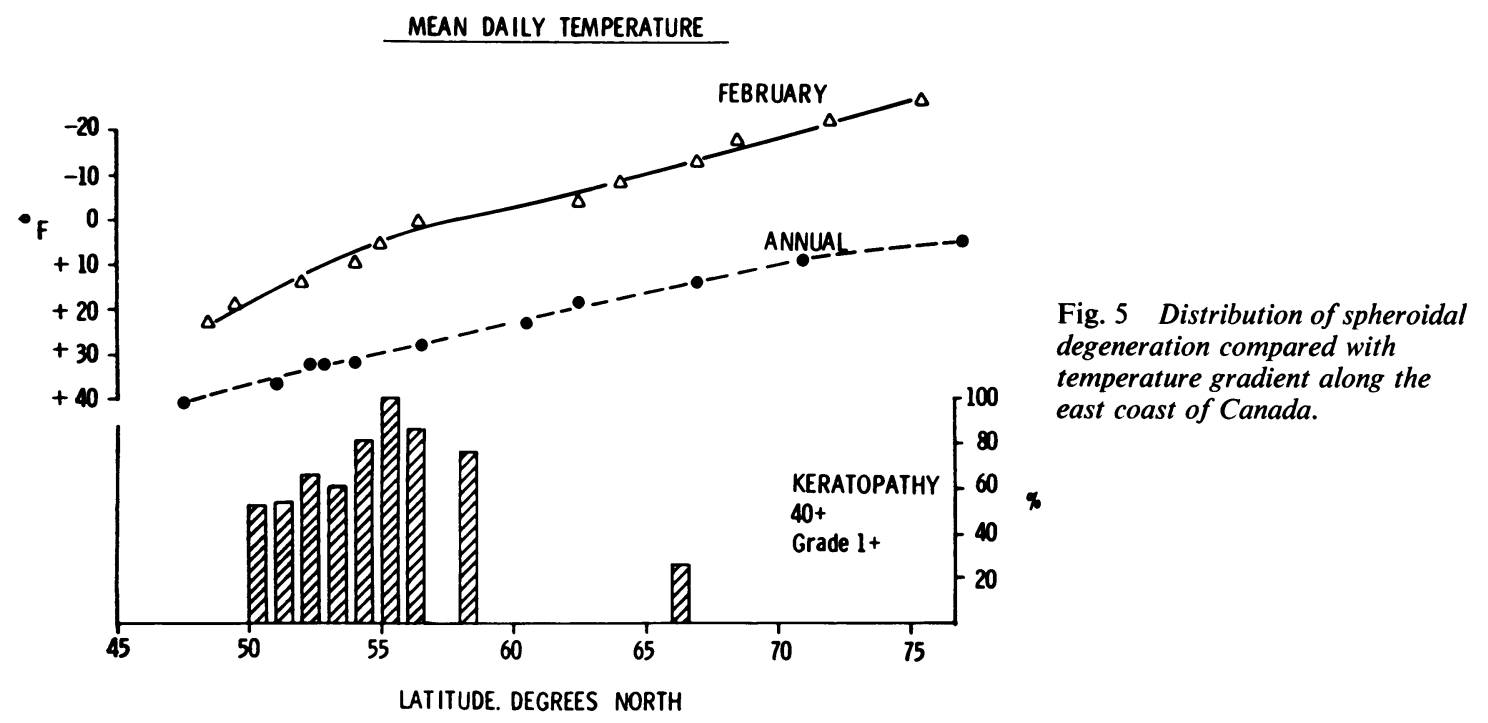

Fig. 6 Distribution of spheroidal degeneration compared with wind-chill factor at different latitudes.
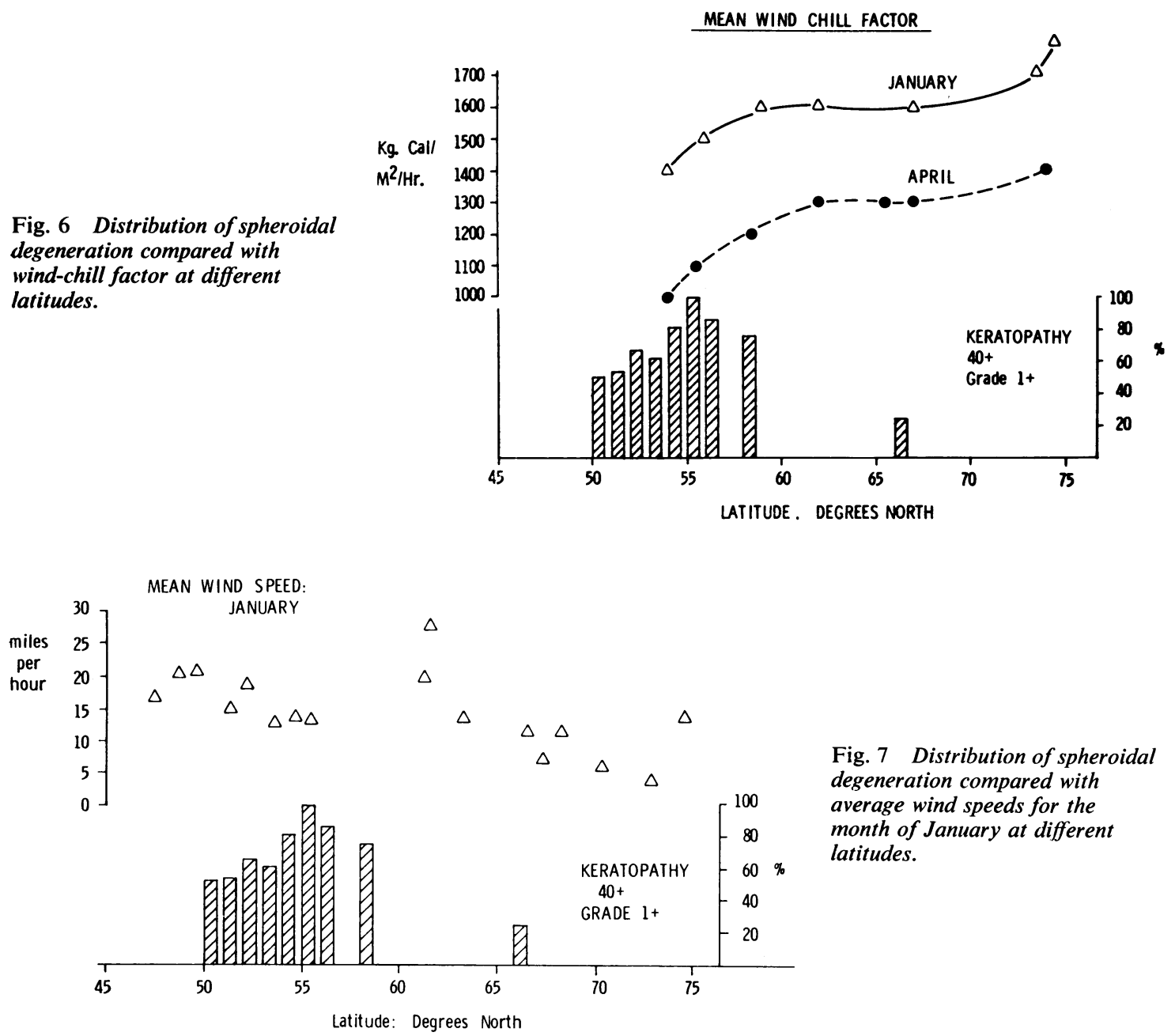

Fig. 7 Distribution of spheroidal degeneration compared with average wind speeds for the month of January at different latitudes. 
Fig. 8 Distribution of spheroidal degeneration compared with number of months with snow cover during which the mean wind speed exceeds 18 miles/h $(29 \mathrm{~km} / \mathrm{h})$.
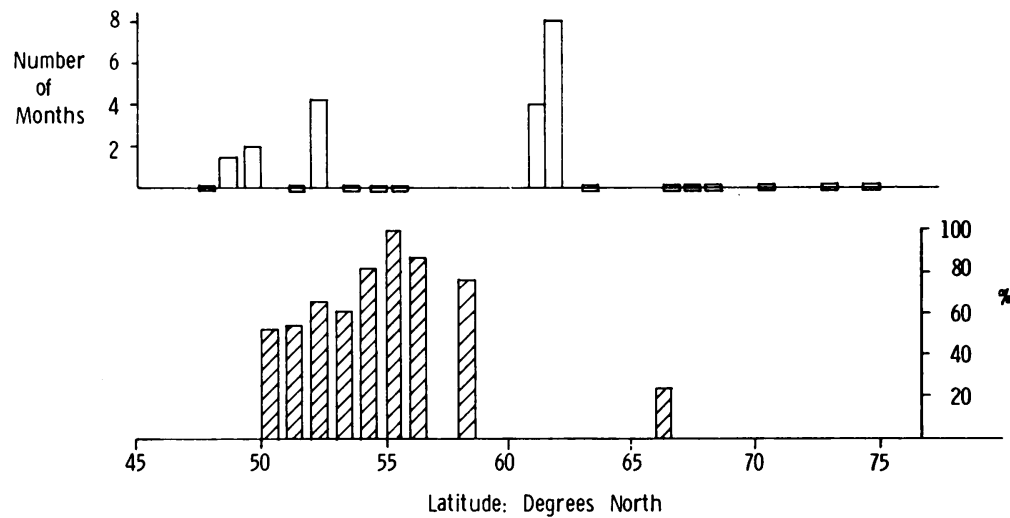

Latitude: Degrees North exposure at the latitudes 61.4 to $61 \cdot 7$ (Resolution Island in Hudson Strait) and a smaller peak in the southernmost part of Labrador and in the Island of Newfoundland.

When total reflected ultraviolet flux reflected from snow and ice was considered, the curve for wavelength $305.5 \mathrm{~nm}$ (from Fig. 1) was compared in Fig. 9 with the geographical distribution of grade 1 spheroidal degeneration already determined for males 40 years and over. Although the peaks do not coincide, the curves fit much better than for any other factor which has been considered. The distribution of females 40 years and over with keratopathy (Fig. 3) fits even more closely to the curve of annual reflected UV flux.

\section{Discussion}

The geographical distribution of spheroidal degeneration in Labrador is best explained by the cumula- tive effect of exposure of the eyes to ultraviolet light reflected from snow and ice.

The countries where corneal degenerations with similar appearance occur were reviewed by Klintworth. ${ }^{6}$ He also listed the multitude of terms applied to what is thought to be fundamentally the same pathological process. One popular name is climatic droplet keratopathy. ${ }^{7}$ It was pointed out to the author by a geographer that the term 'climatic' could not strictly be used for a disease caused by ultraviolet light, since this is not part of the climate but of the wider physical environment. 'Environmental keratopathy' would presumably be acceptable, but is too broad. The descriptive name spheroidal degeneration has therefore been retained for the present, together with Labrador keratopathy when referring to this particular part of the world.

AETIOLOGY IN GENERAL

Neither in Freedman's original study nor in subse-

Fig. 9 Distribution of spheroidal . degeneration in males, in the clinic population, compared with total annual ultraviolet flux, at wavelength $305.5 \mathrm{~nm}$, which could be reflected upwards from snow and ice.

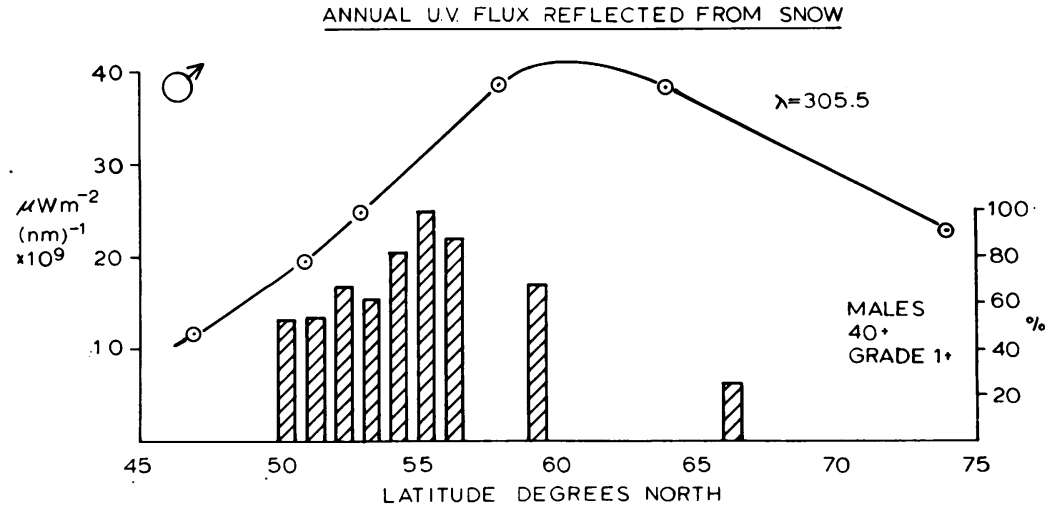


quent observations from Labrador has there been support for a racial or genetic predisposition to this condition. In one community where Indians live just across the river from Caucasian settlers the keratopathy in people of the same age but different races was of the same severity and prevalence. Likewise, people of 3 different racial groups studied in the total population survey at $56^{\circ} 33^{\prime} \mathrm{N}$ had the same age prevalence (Table 2).

No case of nutritional deficiency was identified in the region during the $3 \frac{1}{2}$ years of this study. In the early part of this century nutritional deficiency diseases, especially beri-beri and vitamin A deficiency, were frequent problems. $^{89}$ They affected some communities more severely than others, depending on the local conditions and customs. ${ }^{10}$ Although nutritional deficiency cannot be completely excluded on the epidemiological evidence available as a contributory factor in the older people, the regular gradation of severity of the corneal degeneration by latitude argues against it being the primary cause.

Until recently the economy of the region, and indeed survival, depended entirely on fishing, hunting, and trapping. In the north the Indians, Inuit, and settlers, both men and women, were outdoors most of the year hunting caribou, seals, and other game. In the forested areas the men would also constantly be travelling inland in the winter to collect firewood and lumber for construction. Before 1962 there were no roads to any of the coastal communities included in this study, and access in the winter months was by dog team. The conditions therefore existed for an exceptional degree of exposure to severe environmental conditions.

Evidence was found that Labrador keratopathy was primarily due to exposure of the cornea to an external physical agent, as follows.

The degree of spheroidal degeneration observed in the men was proportional to the amount of time spent hunting, trapping, and collecting wood outdoors. The degeneration did not occur in any male who had not spent a considerable time working at these pursuits, with 2 exceptions: one man with well-developed grade 1 keratopathy said he had spent most of his life working in a power plant; it was not possible to go back to ask him in more detail about any previous occupation. The other exception was a man aged 75 when seen who had retired to Labrador after spending 57 years since the age of 16 in Toronto. He had classical grade 1 keratopathy. However, in the city his occupation throughout life had been outdoors as a painter and as a window cleaner, where he would have been exposed to considerable reflected ultraviolet light.
Within families the grade of corneal degeneration recorded for each sibling was proportional to the amount of time spent outdoors in winter and spring. Thus the brother who was a store keeper and engaged in weekend hunting would have minimal or no corneal change, while the most severe grade of degeneration would be found in the eyes of the most active hunter and trapper.

Women had in general less severe grades of the condition and a lower prevalence. The severity approached that for men only in those regions where the women used to carry on similar work. In the entire $3 \frac{1}{2}$ years of the study no women were found with grade 4 . Four had grade 3 and 3 had grade 2: these all lived in Labrador, most of them in the northern half. With 1 exception they provided a clear history of outdoor life, including trapping and hunting.

The degree of degeneration in 2 eyes was remarkably symmetrical. A total of 6 patients were seen with well developed grade 1 keratopathy in one eye and nothing, or at most a trace, in the other. Five men so affected volunteered on further questioning that the unaffected eye was the one they always kept closed when outdoors in sunlight and snow. Three of them had a strabismus, with or without amblyopia. The sixth of these patients was a woman of 63 with a right exotropia, who said she 'preferred' the left (affected) eye.

Three men were seen with untreated bilateral congenital ptosis and 1 with unilateral congenital ptosis. In each of them the area of cornea affected by spheroidal degeneration was restricted to the narrow inferior exposed strip. In a fifth man with a complete unilateral ptosis since the age of 8 (probably due to trauma) the covered cornea was unaffected, while the exposed eye had the expected degree of degeneration. On the other hand in 3 men in whom ptosis had come on later in life (progressive external ophthalmoplegia or senile ptosis) the upper part of the corneas which were now covered by the upper lids were nevertheless involved by the spheroidal deposits.

HUMIDITY, TEMPERATURE, AND

MICROTRAUMA

It is the relative humidity which determines the rate of evaporation from a surface such as the cornea. Although the total water content of the air in Labrador is low in winter, it is in fact well saturated ( $70-80 \%$ in February). It is only when the cold air comes indoors and is warmed up by many degrees that the relative humidity drops to low levels.

The tear film of all patients with severe degrees of spheroidal degeneration was normal to inspection. 
Symptoms and signs of keratitis sicca were conspicuously absent in the Labrador population. In fact tear deficiency syndromes in general were rare in the whole study area. Only 2 or 3 women in the northern peninsula of Newfoundland needed to take tear replacement drops for mild symptoms. The experience of trappers and hunters as well as of visitors is that tear secretion becomes copious when outdoors in cold or windy weather. In fact a blocked lacrimal duct becomes a substantial handicap to these outdoor workers.

It is most unlikely therefore that desiccation of the cornea could be a significant factor. The perpetuation of the suggestion that low humidity might be the cause of spheroidal degeneration of the cornea in Labrador stems from an incomplete appreciation of the actual climatic conditions.

Bietti and colleagues described a nodular corneal degeneration from the Red Sea area which is thought to correspond to the most severe stage (grade 4) of Labrador keratopathy. ${ }^{11}$ It is interesting that although they described the 'dystrophy' as belonging to 'pays tropicaux à sol aride', they emphasised that there were 3 different zones from which the patients came, with different climatic characteristics. They specified that at Massouah (Massawa) and Dahalah (the Dahlak Islands) the relative humidity was very high. These were areas with severe cases of 'nodular dystrophy'. This has been confirmed by a more recent expedition. There are strong winds in the Dahlak Islands and high temperatures which expedite evaporation, so that salt panning can be carried out, but the relative humidity is high. (Rodger FC, personal communication, 1979).

References to freezing of the cornea under naturally occurring conditions are extremely rare in the ophthalmic literature. Exceptional examples in early aviators and in soldiers were quoted by Forsius. ${ }^{12}$ During the $3 \frac{1}{2}$ years of the study no acute effects of cold on the cornea were recognised. A girl who had travelled a long distance sitting behind her father on a snowmobile (motorised toboggan) developed frost-bite of one upper eyelid with subsequent loss of eyelashes, but there was no detectable effect on the cornea.

Bietti et al. suggested that microtrauma due to wind-blown particles such as sand and dust might be responsible for the 'nodular dystrophy'.11 This idea was revived by Freedman as a possible explanation of the disease in Labrador, ${ }^{1}$ but was later discounted by him as an important factor. ${ }^{\text {? }}$

The acute results on the cornea of wind-blown ice particles have in fact been clearly described by Forsius. ${ }^{12}$ Epithelial erosions, stainable with fluorescein, were seen in people who had been driving a snowmobile in temperatures of $-30^{\circ} \mathrm{C}$ or $-40^{\circ} \mathrm{C}$ for only 30 minutes. These corneal lesions were most conspicuous centrally in the cornea, healed within 24 hours without demonstrable permanent changes, and did not correspond to the changes of Labrador keratopathy.

Hunters familiar with the whole coast emphasised that storm conditions were more severe in the northernmost part of Labrador, where there was no shelter if people were caught out in bad weather, than at the $55^{\circ}$ latitude. Wind maps also show that the greatest velocities of wind in the area extend in a tongue west from the Labrador Sea into the Hudson Strait, between the northern tip of Labrador and the southern end of Baffin Island. The few people from that latitude seen in this study are not among those with severe disease. The inverse relationship of the curves for the mean wind speeds in the Labrador latitudes and for percentage of the clinic population with keratopathy (Fig. 7) can perhaps be partly explained by the suggestion that the lower speeds at $55^{\circ} \mathrm{N}$ would allow the hunters and trappers to be outdoors on more days and for longer periods, and therefore more exposed to another physical agent.

\section{ULTRAVIOLET RADIATION}

Kinsey and Cogan identified experimentally the wavelength responsible for acute photophthalmia or snow-blindness in rabbits. ${ }^{13}$ The corneas had a peak sensitivity to radiation damage in the UV range at $288 \mathrm{~nm}$, with a sharp decline to either side of the peak. The long wavelength limit of the action spectrum lay somewhere between 306 and $326 \mathrm{~nm}$. Although the peak for absorption by the corneal epithelium corresponded to that of nucleoprotein $(265 \mathrm{~nm})$, the peak of the action spectrum for snowblindness corresponded more nearly to the absorption peak of serum albumin and globulin $(280 \mathrm{~nm})$.

For chronic UV absorption by the cornea to be the aetiological agent for spheroidal degeneration it would be expected that snow-blindness would be a common feature of the histories of the affected patients. This was in fact found (Table 4). A negative history for snow-blindness in an individual, on the other hand, does not preclude UV light as the agent responsible, because repeated absorption of UV light by components in the cornea can be taking place at energy levels below the threshold for snowblindness. There also seemed to be a wide range of susceptibility to snow-blindness between different people at the same latitude.

In Table 4 'frequently' indicates those who said they had been snow-blind more than 5 times. The affected people were put in the column indicated by 'yes' if they did not specify the number of times, said they had been snow-blind 5 times or fewer, or 
Table 4 The numbers of people moderately and severely affected with spheroidal degeneration from whom a history regarding previous snow-blindness was obtained

\begin{tabular}{lrrrrr}
\hline & \multicolumn{3}{l}{ History of snow-blindness } \\
\cline { 2 - 6 } Group & Frequently* & Yes* & No & $\begin{array}{l}\text { Not } \\
\text { recorded }\end{array}$ & Totals \\
\hline Grade 3, males & 42 & 23 & 10 & 5 & 80 \\
Grade 3, females & 0 & 1 & 3 & 0 & 4 \\
Grade 2, males & 31 & 33 & 7 & 6 & 79 \\
Grade 2, females & 1 & 2 & 0 & 0 & 3 \\
Totals & 74 & 59 & 20 & 11 & 166 \\
\hline
\end{tabular}

"See text for definitions.

said 'occasionally'. Many of the patients in Labrador tell of being snow-blind repeatedly each spring and of having to be in a darkened room for up to 3 days before being able to go out again. This was particularly true in their younger days. Sun glasses, if they could be obtained at all, could not be replaced until the next season if lost. When one is walking fast or working in low temperatures glasses tend to steam up; sunglasses would be removed so that hunting could continue. Glasses with metal frames or side pieces would also frequently be removed by a person standing still because they froze to the skin of the face. It is necessary to experience these winter conditions in Labrador to appreciate why protection for the eyes against reflected sun is often not worn even though it might be desirable.

Urbach in his experiments with dummy heads or 'mannikins' has shown that, for the region of the eyes to receive a high dose of UV irradiation, the light must be reflected from a ground cover such as sand or snow. ${ }^{14} \mathrm{~A}$ shade such as a cap then provides virtually no protection to the regions of the orbits. Thus the conditions exist in Labrador under which chronic damage to the eyes by ultra-violet could occur.

The histochemistry of corneal tissue from Labrador has been described previously. ${ }^{15}$ The spheroidal deposits consist wholly or partly of protein, but their exact chemical composition has not yet been defined.

None of the authors who have considered low relative humidity, low temperatures, or microtrauma from ice particles have offered an explanation of the mechanism of action by which these possible climatic or physical agents would cause the deposition of spheroids containing protein in the superficial corneal stroma. When we turn to ultraviolet light, however, we are considering an agent which is well known to produce biological effects, particularly the alteration of proteins.

The immediate effects of UV light on organic molecules are at least partly understood. ${ }^{1617}$ The most sensitive amino acids to the action of UV light are histidine, tryptophan, methionine, cysteine, and tyrosine. Pirie studied the products of tryptophan breakdown in lens proteins and serum albumin exposed to sunlight. ${ }^{18}$

When sections of cornea from patients with Labrador keratopathy were treated by an immunoperoxidase technique, with the use of antibodies to a variety of plasma constituents, the droplets were located in the areas of greatest concentration of these proteins, especially albumin, immunoglobulin $\mathrm{G}$, and immunoglobulin $A \cdot{ }^{15}$ It is known that albumin and immunoglobulin $\mathrm{G}$ are normally present in the cornea as a result of diffusion from the limbal vessels. ${ }^{19} 20$

Although he did not specifically suggest plasma proteins, Klintworth also listed the evidence that the concretions were not synthesised in the corneal stroma or deposited by the degradation of formed components. ${ }^{21} \mathrm{He}$ concluded that the 'droplets' consisted of material migrating in from outside the cornea.

The cornea is the only part of the body where plasma proteins are exposed directly to light while diffusing across a tissue which is normally devoid of blood vessels. The hypothesis was therefore advanced that the ultraviolet light reflected from the ice and snow in the Labrador spring is being absorbed by sensitive amino acids of plasma proteins normally present in the cornea, so that some of these proteins are degraded and accumulate in the superficial stroma. ${ }^{15}$

Rodger and coauthors concluded that ultraviolet was responsible for Bietti's form of the disease in the Dahlak Islanders, reflected in that locality from coral sand contaminated with salt. ${ }^{22}$

If these arguments for the ultraviolet aetiology of spheroidal degeneration are accepted, then a chronic eye condition can be added to the detrimental effects already known to be caused in humans by naturally occurring solar UV light: malignant tumours of the skin; skin tumours in heritable disease such as xeroderma pigmentosum; sunburn of the skin; 'aging' of the skin (wrinkling and loss of elasticity); photoallergy and phototoxicity; and acute corneal epithelial damage in snow-blindness.

These effects have assumed new importance since the recent urgent interest in the properties of the ozone layer of the stratosphere. Although recent work indicates that the deleterious effects of emissions from supersonic aircraft has been much exaggerated, a new report suggests that the longterm effects of the fluorocarbon propellants used in spray cans may have been underestimated ${ }^{23}$ A $15 \%$ reduction of ozone levels over the next several 


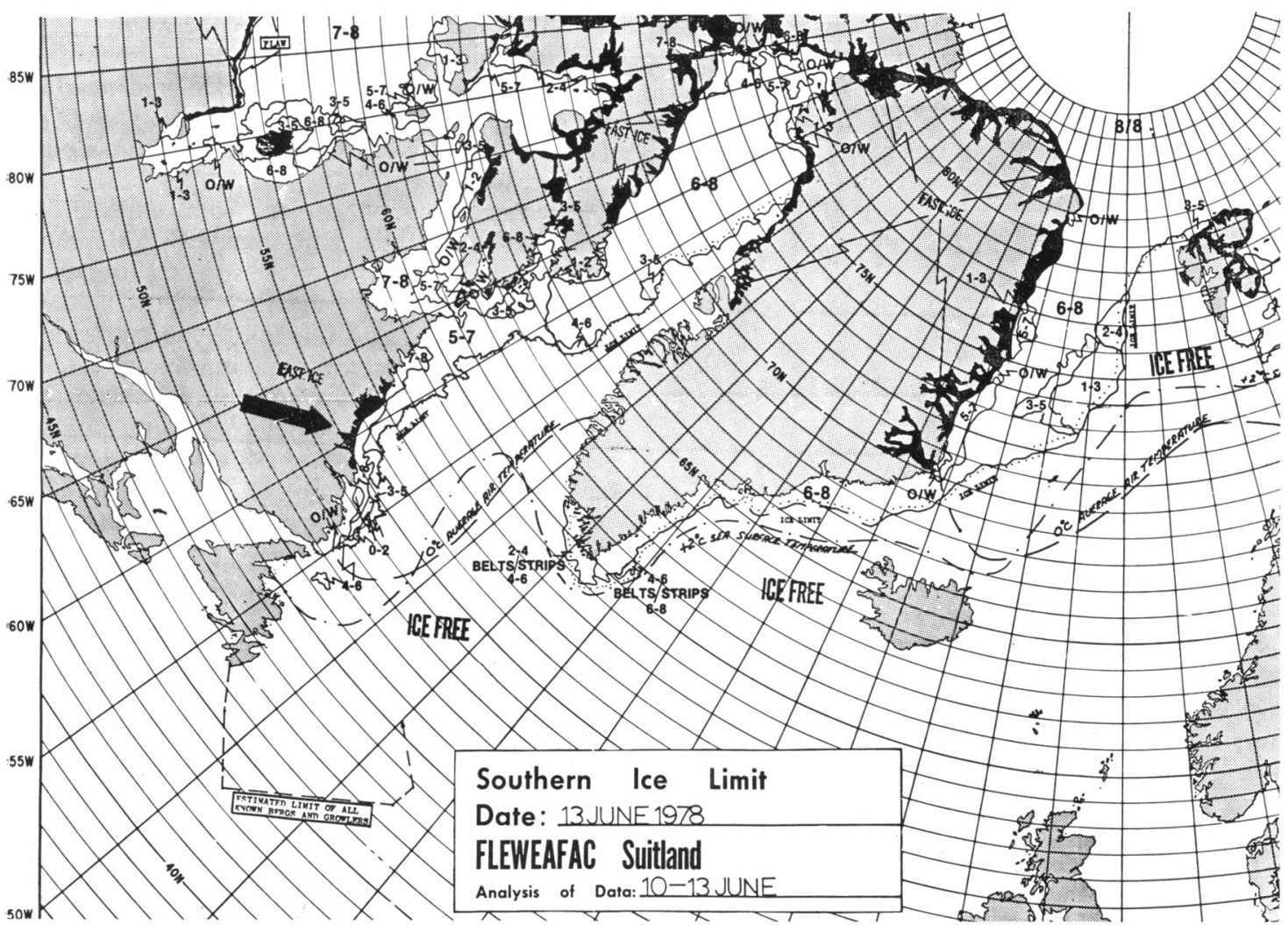

Fig. 10 Map of ice limits for 13 June 1978. Persistent fast shore ice in Labrador between latitude $54^{\circ} 40^{\prime}$ and $57^{\circ} 40^{\prime}$ indicated by arrow. Reproduced by permission of the Commanding Officer of the US Naval Polar Oceanography Center (formerly the Fleet Weather Facility, Suitland).

decades has been predicted. This would be expected to result in an increase in ultraviolet flux at the earth's surface at $40^{\circ} \mathrm{N}$ of at least $40 \%$, and more at the equator. ${ }^{24}$ It is therefore possible that a reduction in the ozone shield could allow spheroidal degeneration of the human cornea to occur with greater prevalence in the latitudes of this study and to be seen more frequently under temperate conditions.

Another implication follows the introduction of 8-methoxypsoralen to enhance the effect of UV therapy for psoriasis. No effect on the eye has so far been noted. However, it may be too early to exclude a long-term effect of naturally occurring UV light on the corneas of patients taking these drugs systemically.

GEOGRAPHICAL PECULIARITY OF LABRADOR The importance of the southerly latitude of Labrador in giving rise to conditions favourable to the development of the keratopathy is underlined by Forsius. ${ }^{12} \mathrm{He}$ recorded a much lower severity in Lapland, and also among Inuit in Igloolik, Northwest Territories of Canada, than has been found in Labrador. With very few exceptions the degeneration seen in these locations did not extend to the pupillary area and thus did not affect visual acuity. Forsius pointed out that snow-blindness is less of a problem in the northern latitudes of the Arctic regions than in the southern parts, where the sun rises higher above the horizon. Wyat ${ }^{25}$ also emphasised the lower frequency of spheroidal degeneration in the North-west Territories than in Labrador.

The very low prevalence and severity of the degeneration in the high Arctic was confirmed by Leith and myself during a recent visit to the communities of Resolute Bay, Grise Fjord, Pond Inlet, and Arctic Bay (between latitudes $72^{\circ}$ and $77^{\circ} \mathrm{N}$ ). Among a total of 86 people aged 40 years or over seen in the 4 settlements only 3 Inuit were found 
who could be classified as having a very early grade 1 degeneration: a man of 75 from Pond Inlet; a man of 58, also from Pond Inlet, who had chronic glaucoma so that the early spheroidal degeneration could not necessarily be regarded as primary; and a woman of 64 who had lived on the Quebec shore of Hudson Bay at latitude $58^{\circ} 30^{\prime}$ until she moved north in 1955. Snow blindness was reported by the hunters to occur between latitudes $72^{\circ}$ and $77^{\circ} \mathrm{N}$ but much less severely and frequently than in Labrador.

The climate of the Newfoundland region is unique in that the Labrador Current carries Arctic marine conditions further south than anywhere else in the world. The warm Gulf Stream becomes the North Atlantic Current, which divides as it approaches Europe. A northern flow-the Irminger Current-sweeps west from Iceland and around the southern tip of Greenland to become the West Greenland Current, allowing the south-west coast of Greenland at sea level to be relatively warm for its latitude. On the opposite side of the Davis Strait the Labrador Current, fed by a flow from the Arctic basin through the archipelago of islands and also by waters from northern Greenland, passes south along the eastern edge of Canada. It brings cold water and icebergs down into the bays of Newfoundland and into the shipping channels (Fig. 10). This current causes the mean temperature to be much colder than would be expected for an area on the same latitude as Britain, and determines the forms of life in the whole region.

Fig. 10 shows the ice map for 13 June 1978. Not only is there pack ice down to the south-east corner of Labrador, but there is solid ice fastened along the shore from $54^{\circ} 40^{\prime}$ to $57^{\circ} 40^{\prime} \mathrm{N}$ (indicated by arrow). The sun would now be at almost its highest angle for the year. Yet the men in these communities are still out all day hunting seals on the ice.

The NOAA/NESS composite ice limits maps for the northern hemisphere, derived from satellite data, emphasise the very unusual situation on the east coast of Canada. In Labrador the sea ice in May extends south to latitude $53^{\circ}$, while in Europe the nearest ice is at Spitzbergen at $78^{\circ}$. The only other coastal areas in the northern hemisphere where similar ice conditions occur so far south are in Hudson Bay and, in the eastern Soviet Union, the Sea of Okhotsk. It may be predicted that spheroidal degeneration would be seen in moderately severe form and with the same frequency as in Labrador in outdoor workers in these regions. It is therefore interesting that the ophthalmologist who has been responsible for eye clinics in both areas sees the keratopathy with much greater prevalence and severity on the Quebec shore of southern
Hudson Bay than in any of the communities of Baffin Island, further north (Leith $\mathrm{AB}$, personal communication, 1979).

I am indebted to J. Hostetter, RN, eye nurse with the International Grenfell Association; D. Fantham for help with the calculations; F. Humby of the Gander Weather Office; A. D. Gates of Environment Canada, Bedford, NS; J. B. Maxwell of the Canadian Climate Centre, Downsview, Ontario; the Commanding Officer of the US Naval Polar Oceanography Centre (formerly the Fleet Weather Facility, Suitland) for use of Eastern Arctic sea ice analysis charts; and the US Department of Commerce, NOAA/NESS, for satellite maps of snow and ice limits. I also thank $\mathrm{Dr} \mathrm{A}$. Leith and Dr M. Flanders for their support, and B. Humby, C. George, and the station nurses of the IGA for their unfailing assistance.

This investigation was supported by the E. A. Baker Foundation of the Canadian National Institute for the Blind.

\section{Appendix}

CALCULATION OF ULTRAVIOLET RADIATION REFLECTED FROM EARTH'S SURFACE

The ultraviolet flux near the earth's surface has 2 components, direct and diffuse. The diffuse flux is produced by repeated scattering or reflection of the radiation initially removed from the solar beam. Unless there is no ground reflection, this diffuse flux has both a downward and upward component. The downward component of the diffuse flux is referred to as 'skylight' or 'global' radiation.

This diffuse component is very important in the total flux. The ratio of direct to diffuse flux varies with wavelength, the angle of the incident solar beam, and ozone amounts.

The total amount of UV radiation reaching the ground is therefore governed by several factors: the angle of incidence of solar radiation, i.e., the zenith angle of the sun; absorption by ozone in the atmosphere; scattering by air molecules; scattering and absorption by clouds and aerosols; reflection by clouds; reflection by the ground surface; and the altitude of the station above sea level.

For each latitude indicated in Table 5 calculations have been made of the component of the ultraviolet light which is reflected upwards from the ground during the months when it is covered by snow, and the water by ice.

The measure of UV radiation, the monochromatic flux, is defined by Sundararaman and colleagues ${ }^{5}$ as the amount of radiant energy crossing unit horizontal area in unit time,

Table 5 Latitudes for which ultraviolet flux was calculated, with average periods of snow and ice cover. The altitudes above sea level are given for the 6 stations from which ozone measurements were available

\begin{tabular}{llllc}
\hline Latitude & Freeze-up & Break-up & $\begin{array}{l}\text { Recording } \\
\text { station }\end{array}$ & $\begin{array}{r}\text { Altitude } \\
\text { (metres) }\end{array}$ \\
\hline $74^{\circ} \mathrm{N}$ & 5 Oct. & 19 July & Resolute & 84 \\
$64^{\circ} \mathrm{N}$ & 7 Nov. & 5 July & Fairbanks, Alaska & 138 \\
$58^{\circ} \mathrm{N}$ & $16 \mathrm{Dec}$. & $22 \mathrm{June}$ & Churchill, Manitoba & 49 \\
$53^{\circ} \mathrm{N}$ & 31 Dec. & $22 \mathrm{May}$ & Goose Bay & 44 \\
$51^{\circ} \mathrm{N}$ & 7 Jan. & 7 May & Moosonee, Ontario & 10 \\
$47^{\circ} \mathrm{N}$ & $15 \mathrm{Jan}$. & 12 April & Caribou, Maine & 190 \\
\hline
\end{tabular}


this energy belıy contained in a unit wavelength interval, centred on the particular wavelength of interest.

To arrive at figures which could be compared with the geographical distribution of spheroidal degeneration of the cornea, a number of assumptions and approximations were made.

Sundararaman and colleagues ${ }^{5}$ give tables for the daily mean flux for 5 different wavelengths calculated for each month of the year for stations around the world where ozone measurements have been recorded. Only 7 of these are in the latitudes of the western hemisphere with which this paper is concerned, and only 2 in the exact geographical area under consideration (Resolute, approximately $74^{\circ} \mathrm{N}$, and Goose Bay, $53^{\circ} \mathrm{N}$ ). For this reason the figures for 4 other stations shown in Table 5 were used as if they were located on the east coast of Canada.

A small approximation is involved here in that the lines joining points of equal annually averaged daily mean fluxes are thought to slope slightly southward as one crosses the North American continent from west to east. These longitudinal variations are brought about by the redistribution of ozone by the direction of stratospheric circulation.

Sundararaman et al. ${ }^{5}$ assumed clear and cloudless conditions for their calculations. This assumption has been kept for the purposes of the present paper, since we are more interested in a comparison of values between the different latitudes rather than absolute figures of flux. The flux reduction factor given in their report for percentage of cloudy days in Philadelphia might give variations of up to $5 \%$ in the figures if it could correctly be applied to the extremes of cloud cover encountered along the whole eastern Canadian seaboard, published as tenths of sky covered.

Another assumption concerns station altitude (Table 5) UV flux increases almost linearly with station altitude, the rate of increase being dependent on both solar zenith angle and wavelength. Sundararaman et al. ${ }^{5}$ show that for a $60^{\circ}$ zenith angle the increase in flux over the sea-level values are between 7 and $8 \%$ at 1 kilometre, for both wavelengths $300.4 \mathrm{~nm}$ and $311.4 \mathrm{~nm}$. Therefore the possible error introduced by the fact that the highest ozone station, Caribou, is 190 metres compared with the coast of Newfoundland at sea level is a little over $1.5 \%$. In fact at latitude $47^{\circ} \mathrm{N}$ in Newfoundland there is no stable sea ice, so that any exposure to UV light by hunters or outdoor workers is more likely to take place on cliffs or inland plateaux which themselves may be at 190 metres altitude.

The Indians resident at $55^{\circ} 55^{\prime}$ north hunt on higher terrain inland, where the altitude is up to 700 metres. On the assumption that they spent all their time at that altitude, the total upward ultraviolet flux to which they were exposed would be $5 \%$ above the sea-level value. All the other patients studied for Labrador keratopathy lived only a few metres above sea level and hunted on the sea ice or at low altitudes on land.

Few figures have been published for the albedo (reflectivity) of snow for ultraviolet light. Albedo is a complex property. For example, for visible light it varies with solar elevation, cloud cover, grain size of the snow, and recrystallisation in warm weather. ${ }^{26}$ The particle and crystal orientation of the snow surface depends in turn on wind direction. The resulting polarising effect will result in greater or less absorption of polarised sunlight, depending on the elevation and direction of the sun and of the observer. ${ }^{27}{ }^{28}$ The albedo for ultraviolet wavelengths is presumably dependent on the same factors. For the area of this study the measurement of these variables was not available. Since the concern was more with the comparison between different latitudes rather than the absolute values for UV flux, a general figure of $90 \%$ was taken. ${ }^{29}$

Reflection from the ground can enhance the total, direct plus diffuse, downward flux of UV radiation. Greater enhancement occurs for lower ozone amounts, shorter wavelength, and higher albedo. Sundararaman et al..$^{5}$ give examples of enhancement factors for flat ground. It was felt for the purpose of the present calculations that, although the enhancement factor would alter the steepness of the resulting curve, it would not alter the basic shape of the curve being compared with the distribution of the disease.

\section{References}

1 Freedman A. Labrador keratopathy. Arch Ophthalmol 1965; 74: 198-202.

2 Fraunfelder FT, Hanna C, Parker JM. Spheroid degeneration of the cornea and conjunctiva. I. Clinical course and characteristics. Am J Ophthalmol 1972; 73: 821-8.

3 Johnson GJ, Ghosh M. Labrador keratopathy: clinical and pathological findings. Can J Ophthalmol 1975; 10: 119-35.

4 Thomas MK, Boyd DW. Wind chill in northern Canada. Canadian Geographer 1957; 10: 29-39.

5 Sundararaman N, St John D, Venkateswaran SV. Solar ultraviolet radiation received at the earth's surface under clear and cloudless conditions. Washington: Department of Transportation 1975.

6 Klintworth GK. The cornea-structure and macromolecules in health and disease. Am J Pathol 1977; 89: 719808.

7 Freedman A. Climatic droplet keratopathy. I. Clinical aspects. Arch Ophthalmol 1973; 89: 193-7.

8 Little JM. Beriberi caused by fine white flour. JAMA 1912; 58: 2029-30.

9 Aykroyd WR. Beriberi and other food-deficiency diseases in Newfoundland and Labrador. J Hyg 1930; 30: 357-86.

10 Appleton VB. Observations on deficiency diseases in Labrador. Am J Public Health 1921; 11: 617-21.

11 Bietti GB, Guerra P, Ferraris De Gaspare PF. La dystrophie cornéenne nodulaire en ceinture des pays tropicaux à sol aride; contributions cliniques et anatomopathologiques. Bull Soc Ophtalmol Fr 1955; 68: 101-29.

12 Forsius $\mathrm{H}$. Climatic changes in the eyes of Eskimos, Lapps and Cheremisses. Acta Ophthalmol (Kbh) 1972; 50: $532-8$.

13 Cogan DG. Kinsey VE. Action spectrum of keratitis produced by ultraviolet radiation. Arch Ophthalmol $1946 ; 35: 670-7$.

14 Urbach F. Geographic pathology of skin cancer. In: Urbach F, ed. The Biologic Effects of Ultraviolet Radiation. Oxford: Pergamon Press, 1969; 635-50.

15 Johnson GJ, Overall M. Histology of spheroidal degeneration of the cornea in Labrador. $\mathrm{Br} J$ Ophthalmol 1978; 62: 53-61.

16 Norins AL. Immediate effects of light. In: Urbach F, ed. The Biologic Effects of Ultraviolet Radiation. Oxford: Pergamon Press, 1969; 31-6.

17 Yeargers E. Ultraviolet light effects on proteins. In: Urbach F, ed. The Biologic Effects of Ultraviolet Radiation. Oxford: Pergamon Press, 1969; 37-46.

18 Pirie A. Photo-oxidation of proteins and comparison of photo-oxidised proteins with those of the cataractous human lens. In: Michaelson IC, Berman ER, eds. Causes and Prevention of Blindness. New York: Academic Press, 1972; 547-53.

19 Maurice DM, Watson PG. The distribution and movement of serum albumin in the cornea. Exp Eye Res 1965; 4: $355-63$.

20 Allansmith MR, Whitney CR, McClellan BH, Newman LP. Immunoglobulins in the human eye. Location, type and amount. Arch Ophihalmol 1973; 89: 36-45. 
21 Klintworth GK. Chronic actinic keratopathy-a condition associated with conjunctival elastosis (pingueculae) and typified by characteristic extracellular concretions. Am J Pathol 1972; 67: 327-42.

22 Rodger FC, Cuthill JA, Fydelor PJ, Lenham AP. Ultra-violet radiation as a possible cause of corneal degenerative changes under certain physiographic conditions. Acta Ophthalmol (Kbh) 1974; 52: 777-85.

23 Committee on Impacts of Stratospheric Change: Panel on Stratospheric Chemistry and Transport. Stratospheric Ozone Depletion by Halocarbons: Chemistry and Transport. Washington: National Academy of Sciences; 1979.

24 Environmental Studies Board: Ad hoc panel on the biological impacts of increased intensities of solar ultraviolet radiation. Biological Impacts of Increased Intensities of
Solar Ultraviolet Radiation. Washington: National Academy of Sciences, 1973.

25 Wyatt HT. Corneal disease in the Canadian north. Can J Ophthalmol 1973; 8: 298-305.

26 Liljequist GH. Radiation, and wind and temperature profiles over an Antarctic snow-field-a preliminary note. Proceedings of the Toronto Meteorological Conference 1953: 78 .

27 Schwerdtfeger P. Effect of polarization on the albedo. Nature 1964; 202 : 894.

28 Rao, CRN. Polarization and albedo. Nature 1964; 204: $277-8$.

29 Buettner KJK. The effects of natural sunlight on human skin. In: Urbach F, ed. The Biologic Effects of Ultraviolet Radiation. Oxford: Pergamon Press, 1969; 237-49. 